\title{
Micro-grid System Based on Renewable Power Generation Units
}

\author{
R. Ahshan*, M. T. Iqbal, George K. I. Mann and John E. Quaicoe \\ Faculty of Engineering and Applied Science \\ Memorial University, St. John's, NL, A1B3X5 \\ *Email: rahshan@mun.ca
}

\begin{abstract}
Micro-grid system is currently a conceptual solution to fulfill the commitment of reliable power delivery for future power systems. Renewable power sources such as wind and hydro offer the best potential for emission free power for future micro-grid systems. This paper presents a micro-grid system based on wind and hydro power sources and addresses issues related to operation, control, and stability of the system. The micro-grid system investigated in this paper represents a case study in Newfoundland, Canada. It consists of a small hydro generation unit and a wind farm that contains nine variablespeed, double-fed induction generator based wind turbines. Using Matlab/Simulink, the system is modeled and simulated to identify the technical issues involved in the operation of a micro-grid system based on renewable power generation units. The operational modes, technical challenges and a brief outline of conceptual approaches to addressing some of the technical issues are presented for further investigation.
\end{abstract}

Keywords: Renewable power generation, Distributed generation, Micro-grid, Simulation.

\section{NOMEnClature}

$\begin{aligned} \text { CERTS } & \text { Consortium for electric reliability techno- } \\ \text { FC } & \text { logy solutions } \\ \text { HGU } & =\text { Hydro generl } \\ \mathrm{MG} & =\text { Micro-grid } \\ \mathrm{MCFC} & =\text { Molten carbonate fuel cell } \\ \mathrm{NEDO} & =\text { New energy and industrial technology } \\ \text { NPEP } & =\text { Newfoundland power energy plan } \\ \mathrm{PV} & =\text { Photovoltaic } \\ \text { PCC } & =\text { Point of common coupling } \\ \text { PAFC } & =\text { Phosphoric acid fuel cell } \\ \text { SOFC } & =\text { Solid oxide fuel cell } \\ \text { WT } & =\text { Wind turbine } \\ \text { WPGS } & \text { Wind power generation system }\end{aligned}$

\section{INTRODUCTION}

The demand for more power combined with interest in clean technologies has driven researchers to develop distributed power generation systems using renewable energy sources [1-3]. On the other hand, the integration of a large number of distributed generations into distribution network is restricted due to the capacity limitation of the distribution networks and their unidirectional power flow behaviour [2, 4, 5]. Such barriers have motivated researchers to find an alternative conceptual solution to enhance the distributed generation integration into the distribution networks. An alternative approach called "Micro-grid" was proposed in 2001 as a means of integrating more distributed generations into the distribution networks [5].

Distributed generation in micro-grid operation provides benefits to the utility operators, distributed generation owners and consumers in terms of reliable power supply, transmission loss compensation, reduction in transmission system expansion and enhancement of renewable power penetration.

A review of the existing literature reveals that the first microgrid architecture was proposed by R. H. Lasseter [5, 6], and called CERTS micro-grid. The CERTS micro-grid generally assumes converter-interfaced distributed generation units based on both renewable and non-renewable power sources. Barnes et al [8] also proposed a micro-grid system under the frame of the European project "Micro-grids". The European micro-grid architecture consists of two PV generators, one wind turbine, battery storage, controllable loads and a controlled interconnection for the local low voltage grid. The NEDO in Japan proposed three micro-grid projects in 2003 [9, 10]. The first NEDO micro-grid ( $1.7 \mathrm{MW}$ ) system comprises different kinds of fuel cells such as MCFC, PAFC, SOFC, and photovoltaic (PV) system and battery storage.The second NEDO micro-grid ( $610 \mathrm{~kW})$ configuration consists of PV, WT, biomass and battery storage. The third NEDO micro-grid ( $750 \mathrm{~kW}$ ) system consists of PV, WT, MCFC, biogas and battery bank, which has very low percentage (13 percent) of renewable energy generation. Micro-grid research in Canada has started in universities with the cooperation of the CANMET energy technology center at Varennes [9]. This research group has identified industry cases, such as the isolated Ramea wind-diesel microgrid system, and the Fortis Alberta grid-tied micro-grid system for investigation. Canada's micro-grid research and development also evolved to develop a test bed for industrial-grade prototype testing and performance evaluation [9]. A study of micro-grid dynamic behavior, along with the control of the micro-generation units is performed by F. Kateraie [7]. This micro-grid system is based on the benchmark system of the IEEE Standard 399-1997 [11], which consists of three generation units comprising a diesel generator or a gas turbine generator, an electronically interfaced distributed generation and a fixed speed wind power generator. Research on micro-grid systems is also found in literature, where the generation units and loads combination are arbitrarily assumed [12-16].

The diverse micro-generation units in a micro-grid system and the desire to integrate more clean power in future power network has led to a focus on a micro-grid system based on renewable power generation units in this research. As a whole, the characteristics of a micro-grid system depend on the size and nature of the micro- 
generation units in the micro-grid, as well as the site, and the availability of the primary energy resources on the site, especially for renewable power sources. Therefore, taking an existing real system is the better approach to investigate the micro-grid system issues rather than assuming or taking a hypothetical system. The objective of this research is to investigate the system behavior and technical issues of a micro-grid system contains renewable power generation units in Newfoundland.

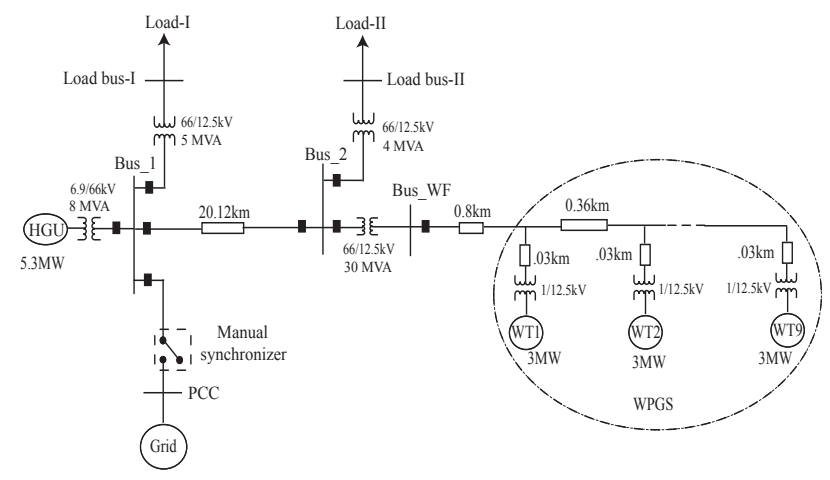

Fig. 1. The micro-grid system currently under investigation

\section{THE MICRO-GRID SYSTEM}

The schematic of the micro-grid system shown in Figure 1 consists of a HGU, a WPGS, and two load areas represented as Load-I (3.94 MW, .9 MVar) and Load-II (2.82 MW, 0.84 MVar). The two load areas are connected through a $20.12 \mathrm{~km}$ transmission line and the two generating systems are connected through a 21 $\mathrm{km}$ transmission line. The wind turbines are connected to bus_2 using its own transmission lines and a $12.5 / 66 \mathrm{kV}, 30$ MVA power transformer. Load bus-II is connected to bus_2 and the power is delivered to the load using a $66 / 12.5 \mathrm{kV}, 4$ MVA power transformer. Load bus-I is connected to bus $\_1$ and the power is delivered to the load using a $66 / 12.5 \mathrm{kV}, 5$ MVA power transformer. The HGU is connected to bus_1 using a $6.9 / 66 \mathrm{kV}, 8$ MVA power transformer. A conventional synchronous generator, equipped with IEEE standard excitation and governor system, is used for the HGU. A $66 \mathrm{kV}$, 1000 MVA grid is connected to bus_1. Both power generation systems operate in grid connected mode. The automatic isolated operation of the HGU is not the current practice of the utility owner, and the WPGS is not allowed to operate in isolated mode. In the event that the grid power is lost due to faults or scheduled maintenance, a black out would result until the HGU comes in operation. Even with the HGU in operation, some load shedding may be necessary since the HGU would not be able to meet the load demand. Therefore, the consequences of the grid outage are the key drivers which dictate the operational modes of the microgrid system.

\section{Operational Modes of The Micro-Grid System}

Technical issues such as control, power balance strategies, operation, protection and storage techniques differ from one micro-grid to another. The main reasons are the integration of high number of distributed power generation units near to the electrical loads, the nature and size of the micro-generation units, and availability of primary energy sources for renewable power generation units.
Considering these reasons, the technical challenges and methods for addressing them for the system shown in Figure 1 have not been investigated yet. This paper investigates the technical challenges associated with the wind farm and hydro generation based micro-grid system. In order to classify the technical challenges for the microgrid system under investigation, three operational modes (Figure 2) are considered: (a) grid connected system, (b) isolated system with wind power generation, and (c) isolated system without wind power generation.
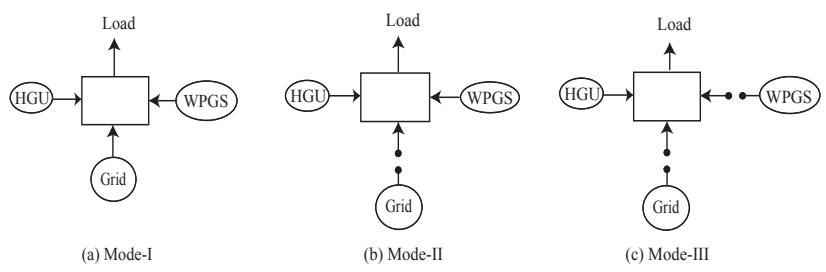

Fig. 2. Micro-grid operational modes

\section{Modeling And Simulation}

The components of the identified system are modeled using MATLAB/SIMULINK software tool. The HGU model is the combination of the model of synchronous generator, hydro turbine and turbine governor system, and excitation system. The synchronous machine electrical system is modeled in a d-q rotor reference frame with the dynamics of stator, rotor and damper windings [17]. The synchronous machine parameters are obtained from Newfoundland Power, Canada and from [18]. Hydro turbine and turbine governor system model is given in [19]. The parameters for the hydro turbine and penstock are obtained from Newfoundland Power, Canada.

The WPGS model consists of dynamic model of nine variablespeed doubly-fed induction generator based wind turbines. Vestas90 wind turbine parameters are used in the developed wind turbine rotor model [20]. The induction machine electrical system is modeled in a d-q synchronously rotating reference frame [17]. Generator parameters are obtained from [20, 21].

The utility grid is represented by an equivalent model of $66 \mathrm{kV}$ three phase voltage source with the short-circuit capacity of 1000 MVA and the reactance to resistance ratio of 22.2 [11]. A constant impedance load model is used in the system. The parameter information about the line, transformer and load are obtained from the utility company, Newfoundland Power.

Simulations for three operational modes (Fig. 2) are performed and the simulation results are presented in the following sections. The measurements presented in the simulation results are in per unit, while the base power is 27 MVA. The simulation was performed for a 60 seconds interval. The wind speed model [22] is used as the wind profile for the wind turbine rotor. WPGS with no output power represents the lack of sufficient wind velocity to generate electric power. The grid is isolated from the system at $\mathrm{t}=5$ seconds because of a fault or regular maintenance in the transmission systems. The fault in the grid transmission systems (unintentional islanding) or their regular maintenance (intentional islanding) is simulated using a three phase circuit breaker with specific time settings. 


\section{A. Mode-I: Grid connected mode}

The simulation results for Mode-I are represented in Figures 3(ad), while WPGS and HGU are connected to the grid. No initial transient indicates the steady-state operation of the system in grid connected mode. Figure 3(a) shows the system frequency in its expected value $60 \mathrm{~Hz}$. Figure 3(c) and 3(b) show the generated power by the HGU, and by the WPGS, while nine wind turbines are in operation. The output of the WPGS varies due to the wind speed variation. Figure 3(d) represents the voltage at bus_1 which is in its rated value. These results indicate that the operation of the HGU and WPGS in grid connected mode is dictated by the grid with the expected system voltages and frequency set by the grid.
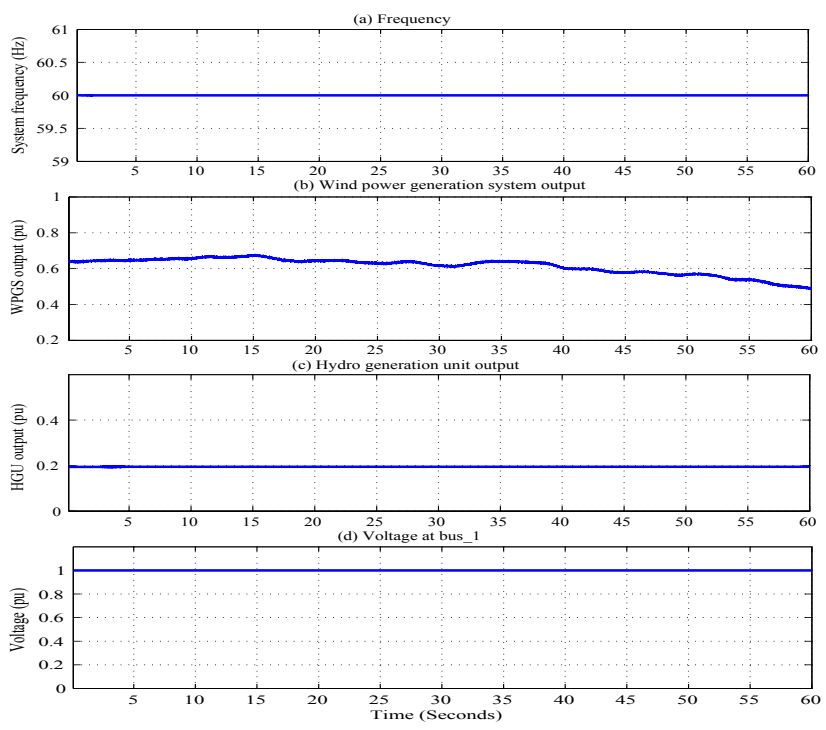

Fig. 3. (a) System frequency (Hz), (b) WPGS output power, (c) HGU output power, (d) Voltage at bus_1

\section{B. Mode-II: Isolated system with wind power generation}

The system operation follows the Mode-I until $t=5$ seconds. After $t=5$ seconds, the grid is isolated from the system. Figure 4(a) shows the micro-grid frequency, which is not in an acceptable range for the micro-grid operation. This indicates that the power generation and consumption is not balanced in the micro-grid system. Figure 4(b) and 4(c) show the power contribution by the two generation units into the micro-gird, while assuming only one wind turbine is in operation in the WPGS after $t=5$ seconds. Voltage at bus_1 is shown in Figure 4(d) which decreases after grid disconnection. This indicates the lack of sufficient reactive power in the micro-grid system, which was actually supplied by the grid in the grid connected mode. More than one wind turbine operating in the WPGS will deliver more active power in the micro-grid system than the load demand. The reactive power demand will also increase in the micro-grid system which results in more reduction in voltage level at different locations in the micro-grid system.

\section{Mode-III: Isolated system without wind power generation}

The system operation follows the Mode-I until $\mathrm{t}=5$ seconds. However, at $\mathrm{t}=5$ seconds, the grid is isolated from the system. Concurrently, the WPGS has no output power as there is insufficient wind resource to produce electricity. This mode of operation
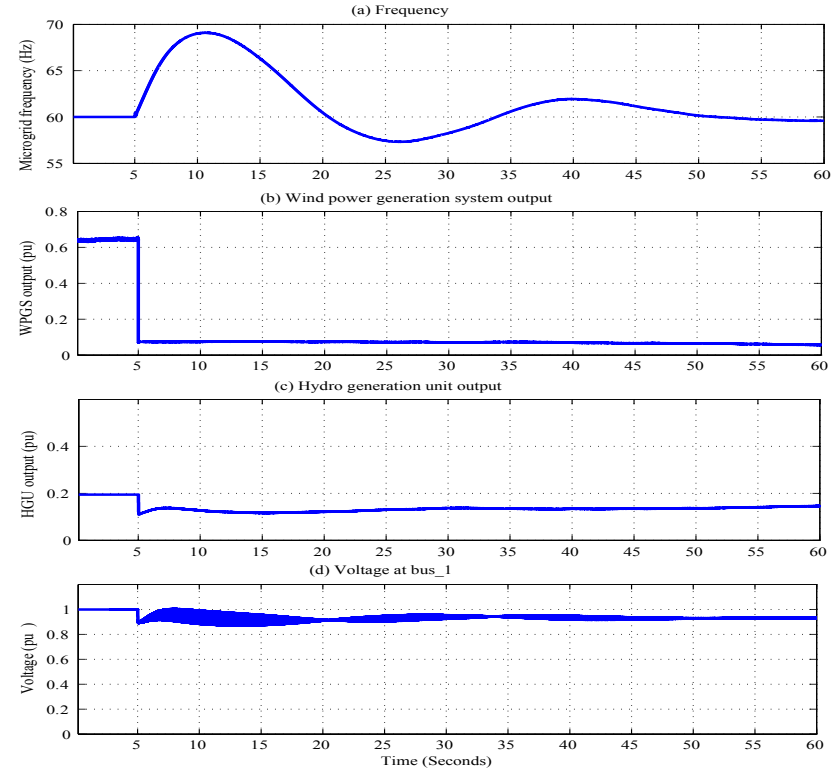

Fig. 4. (a) Micro-grid frequency (Hz), (b) WPGS output power, (c) HGU output power, (d) Voltage at bus_1

is simulated, and the results are shown in Figure 5(a-d). Figure 5(a) shows the micro-grid frequency, which is not tolerable by the system. This also indicates that the power generation and consumption in micro-grid system is not balanced. Figure $5(\mathrm{c})$ shows the HGU output power and the zero output power from the WPGS is shown in Figure 5(b). The voltage level at bus_1 is shown in Figure 5(d) which is much lower than the rated its value. This indicates the requirement for reactive power in the micro-grid system.As the WPGS is not able to deliver power (Fig. 5(b)) after $t=5$ seconds due to the lack of sufficient wind, the requirement of additional power from a reliable storage system is essential.

Based on simulation results, the issues related to micro-grid operation of the system under investigation can be summarized as:

- Active power imbalance between generation units and loads in isolated micro-grid mode when wind power is available. A control scheme is required to maintain active power balance by storing or dumping surplus power. Motor-pump sets can be used to pump water using surplus power. However, a dump load is required to achieve better accuracy in power-frequency balance.

- Active power imbalance between generation units and loads when wind power is not available in isolated micro-grid mode. A suitable storage system along with a control scheme is required to obtain power-frequency balance.

- Reactive power is required during isolated micro-grid operation to maintain the expected voltage level at different buses in the micro-grid system. The reactive power demand can be provided by STATCOM during isolated system with wind power generation and by storage unit during isolated system without wind power generation.

In addition, a control coordinator and monitoring system is required for the micro-grid operation. A load flow based micro-grid monitoring and control coordinator scheme can be chosen for the proposed micro-grid system operation. 

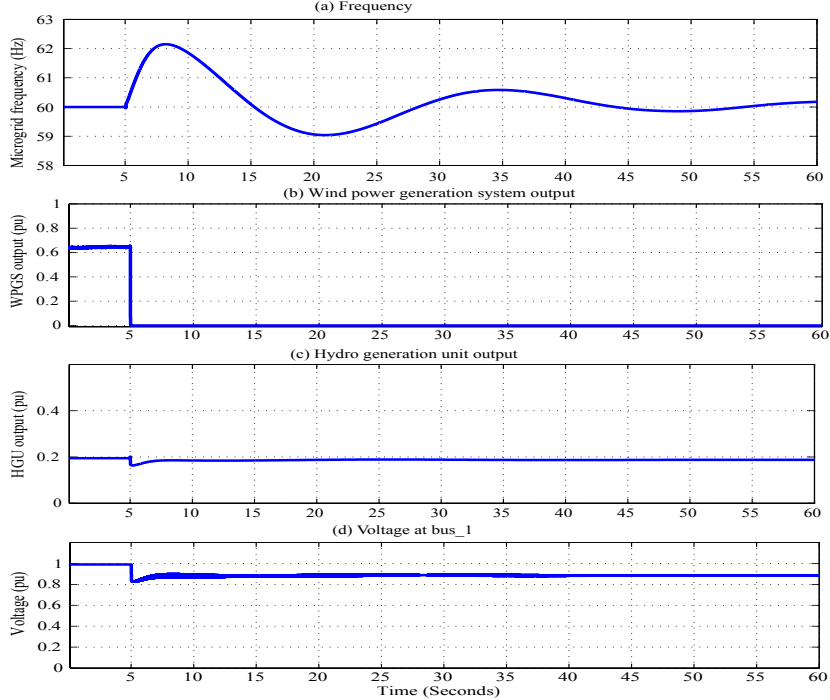

Fig. 5. (a) Micro-grid frequency (Hz), (b) WPGS output power, (c) HGU output power, (d) Voltage at bus_1

\section{CONCLUSIONS}

Micro-grid operation of a system based on renewable power generation units is presented in this paper. The system behavior and technical issues involved with three operational modes in microgrid scheme are investigated. The investigation is performed based on simulation results using Matlab/Simulink software package. Simulation results indicate that dump load and suitable storage system along with proper control scheme are additionally required for the operation of the proposed system in micro-grid scheme. A control coordinator and monitoring system is also required to monitor micro-grid system state and decide the necessary control action for an operational mode. The required control schemes development for the proposed micro-grid system is currently under investigation by the authors.

\section{ACKNOWLEDGEMENT}

This work is supported by a research grant from the National Science and Engineering Research Council (NSERC) of Canada, the Atlantic Innovation Fund (AIF) Canada, and Memorial University of Newfoundland. The author also would like to acknowledge the utility company, Newfoundland Power, Canada for providing the information about the system presented in this paper.

\section{REFERENCES}

[1] T. Ackermann and V. Knyazkin, "Interaction between distributed generation and the distribution network: Operation aspects", Second Int. Symp. Distributed Generations: Power System Market Aspects, Stockholm, Sweden, 2002.

[2] C. Abbey, F. Katiraei, C. Brothers, "Integration of distributed generation and wind energy in Canada", Invited paper IEEE Power Engineering Society General Meeting and Conference, Montreal, Canada, June 18-22, 2006.

[3] Frede Blaabjerg, Remus Teodorescu, Marco Liserre, Adrian V. Timbus, "Overview of control and grid synchronization for distributed power generation systems", IEEE Transactions on Industrial Electronics, Vol. 53, No. 5,October 2006.
[4] F. Katiraei, C. Abbey, Richard Bahry, "Analysis of voltage regulation problem for $25 \mathrm{kV}$ distribution network with distributed generation", IEEE Power Engineering Society General Meeting, Montreal, 2006.

[5] R. H. Lasseter, "Microgrids (distributed power generation)", IEEE Power Engineering Society Winter Meeting, Vol. 01, pp. 146-149, Columbus, Ohio, Feb 2001.

[6] R. H. Lasseter, "Microgrids", IEEE Power Engineering Society Winter Meeting, Vol. 01, pp. 305-308, New York, NY, 2002.

[7] F. Katiraei, M. R. Iravani, P. W. Lehn, "Small signal dynamic model of a micro-grid including conventional and electronically interfaced distributed resources", IET Gener. Transm. Distrib., Vol. 01, Issue 3, pp. 369-378, 2007.

[8] M. Barnes, A. Dimeas, A. Engler, C. Fitzer, N. Hatziargyriou, C. Jones, S. Papathanassiou, M. Vandenbergh, "Micro-grid laboratory facilities", International Conference on Future Power System, November 2005.

[9] N. Hatziargyriou, H. Asano, R. Iravani, C. Marnay, "Micro-gridsAn overview of ongoing research, development and demonstration projects", IEEE Power and Energy Magazine, pp. 78-94, July/August 2007..

[10] S. Morozumi,, "Overview of micro-grid research and development activities in Japan", A Symposium on Micro-grids,Montreal, June 23, 2006.

[11] "IEEE Recommended Practice for Industrial and Commercial Power System Analysis", IEEE Standard., IEEE Std 399-1997, 1997.

[12] M. Shahabi, M. R. Haghifam, M. Mohamadian, S. A. NabaviNiaki, "Microgrid Dynamic Performance Improvement Using a Doubly Fed Induction Wind Generator", IEEE Transactions on Energy Conversion, Vol. 24, No. 1, March 2009.

[13] R. Majumder A. Ghosh G. Ledwich F. Zare, "Load sharing and power quality enhanced operation of a distributed micro-grid", IET Renew. Power Gener., Vol. 3, Iss. 2, pp. 109-119, 2009.

[14] C. Nayar, "Remote Area Micro-Grid System using Diesel Driven Doubly Fed Induction Generators, Photovoltaics and Wind Generators", IEEE International Conferences on Sustainable Energy Technologies, Singapore, pp. 1081-1086, November 24-27, 2008.

[15] C. Nayar, M. Tang, W. Suponthana, "Wind/PV/Diesel Micro Grid System implemented in Remote Islands in the Republic of Maldives", IEEE International Conferences on Sustainable Energy Technologies, Singapore, pp. 1076-1080, November 24-27, 2008.

[16] H. Al-Nasseri, M A Redfern, R. O’Gorman, "Protecting Microgrid Systems containing Solid-State Converter Generation", International Conference on Future Power System, November 2005.

[17] P. C. Krause, O. Wasynczuk, S. D. Sudhoff, "Analysis of Electric Machinery", IEEE Press, 2002.

[18] F. Katiraei, M. R. Iravani, P. W. Lehn, "Micro-Grid Autonomous Operation During and Subsequent to Islanding Process", IEEE Transactions on Power Delivery, vol. 20, no. 1, January 2005.

[19] IEEE Working Group on Prime Mover and Energy Supply Models for System Dynamic Performance Studies, "Hydraulic Turbine and Turbine Control Models for Dynamic Studies", IEEE Transactions on Power Systems, Vol.7, No.1, February, 1992, pp. 167-179.

[20] "Mechanical Operating and Maintenance Manual V90 - 3.0 MW, VCRS 60 Hz", Item no.: 964106.R00, June 2007.

[21] A. Gaillard, P. Poure, S. Saadate, M. Machmoum, "Variable speed DFIG wind energy system for power generation and harmonic current mitigation", Renewable Energy Journal, Vol. 34, pp. 1545$1553,2009$.

[22] M. J. Khan, M. T. Iqbal, "Analysis of a small wind-hydrogen stand-alone hybrid energy system", Applied Energy, Vol. 86, pp. 2429-2442, 2009. 